\title{
Self-reported neck and shoulder pain in adolescents is associated with episodic and chronic migraine
}

Cephalalgia

20I6, Vol. 36(8) 807-8II

(C) International Headache Society 2015 Reprints and permissions: sagepub.co.uk/journalsPermissions.nav DOI: $10.1177 / 0333102415610875$ cep.sagepub.com

@SAGE

\section{Mirjam N Landgraf',2, Rüdiger von Kries ${ }^{3}$, Florian Heinen', Thyra Langhagen ${ }^{1,2}$, Andreas Straube ${ }^{2,4}$ and Lucia Albers ${ }^{3}$}

\begin{abstract}
Aim: The aim of this study was to verify the association between self-reported neck/shoulder pain and migraine and to compare findings of chronic and episodic migraine in adolescents.

Methods: In this cross-sectional study, 601 secondary-school students filled in questionnaires about headache appearance, type and frequency, neck and shoulder pain and lifestyle factors.

Results: The adjusted strength of the association between reported neck and shoulder pain and migraine (assessed in multinomial regression models) increased with the frequency of migraine: less than once a week $(O R=1.40 ; 95 \%$ $\mathrm{Cl}=(0.85-2.30))$, weekly $(\mathrm{OR}=2.14 ; 95 \% \mathrm{Cl}=(\mathrm{I} .42-3.24))$, and at least 15 days/month $(\mathrm{OR}=7.27 ; 95 \%$ $\mathrm{Cl}=(3.42-15.44))$.

Conclusion: In adolescents the association between self-reported neck and shoulder pain and migraine is most pronounced in migraine with a high attack frequency.
\end{abstract}

\section{Keywords}

Adolescents, headache, migraine frequency, neck pain, shoulder pain

Date received: 27 March 2015; revised: 12 August 20I5; accepted: 27 August 2015

\section{Introduction}

An epidemiological survey showed that $69.4 \%$ of adolescents had experienced headache at least once during the previous three months, with $6.9 \%$ suffering from migraine (1). An association of neck/ shoulder pain was specifically found in students with migraine (2). A pathophysiological explanation could be that nociceptive afferents from the painful neck/shoulder areas to the caudal trigeminal nuclei may contribute to the sensation of migrainous headache (trigemino-cervical complex (TCC) (3)). Another explanation may be that recurrent activation of central neurons within the TCC gives rise to referred pain in the neck/shoulder regions innervated by the upper cervical nerves.

As yet it is unclear whether the association between self-reported neck/shoulder pain and headache is equally pronounced in chronic $(\geq 15$ headache days per month) and episodic migraine $(<15$ headache days/month) in adolescents. The objective of this study was to address the following two questions:

1. Are adolescents with chronic migraine more likely to experience neck/shoulder pain than adolescents with episodic migraine?

\footnotetext{
'Department of Pediatric Neurology and Developmental Medicine, Dr. von Hauner Children's Hospital, Ludwig-Maximilians-University of Munich, Germany

${ }^{2}$ German Center for Vertigo and Balance Disorders, Ludwig-MaximiliansUniversity of Munich, Germany

${ }^{3}$ Institute of Social Pediatrics and Adolescent Medicine, Ludwig-

Maximilians-University of Munich, Germany

${ }^{4}$ Department of Neurology, Klinikum Großhadern, Ludwig-MaximiliansUniversity of Munich, Germany
}

\section{Corresponding author:}

Mirjam N. Landgraf, Department of Pediatric Neurology and Developmental Medicine, Dr. von Hauner Children's Hospital, LudwigMaximilians-University Munich, Lindwurmstrasse 4, 80337 Munich, Germany.

Email: mirjam.landgraf@med.uni-muenchen.de 
2. Is the association of migraine and self-reported neck/ shoulder pain greater in adolescents with chronic migraine than in those with episodic migraine?

\section{Methods}

\section{Study population}

Our study sample consists of data from 1674 students recruited for an intervention study with data collection between November 2011 and January 2012 (2). Students in the eighth to 10th grade from 12 grammar schools in the greater Munich area participated. Questionnaires concerning headache and risk factors for headache were completed during a school lesson under the supervision of a medical doctor. For this analysis only students with pure migraine (at least one episode in the last six months) or without any headache (in the last six months) and with full information on headache type, frequency, neck/shoulder pain and possible confounders (stress, consumption of alcohol, coffee, soft drinks containing caffeine, smoking, physical inactivity) were included.

The study was approved by the Data Safety Officer and the Ethics Committee (356/2011) of the University of Munich.

\section{Assessment of headache, neck/shoulder pain and risk factors}

Headache was assessed using the question "Did you experience headache in the last six months?" Children who answered "yes" were asked further questions concerning the characteristics of their headache to enable the type of headache to be classified according to the International Classification of Headache Disorder, third edition beta (4). The questions were based on the Essener Headache Questionnaire (5).

Frequency of headache was assessed using the questions "On how many days in the last three months have you experienced headache?" The average days per month/week were calculated. Frequency was categorized as less than once a week (less than four days per month), at least once a week but not chronic (four to 14 days per month) or chronic migraine (at least 15 days per month).

Students were assumed to suffer from neck/shoulder pain if they answered "yes" to the question "Do you have painful muscles in the neck and shoulder region?"

Other risk factors for migraine were also assessed as described in detail previously (2).

\section{Statistical analysis}

Prevalence of demographics and potential risk factors for headache and means of age were calculated both for the groups of students with self-reported neck/shoulder pain (yes/no) and for the groups with migraine (yes/no). Differences between the groups were assessed using chisquare or $T$ statistics. Risk factors with differences between groups $(p$ value $<0.1)$ for both neck/shoulder pain (yes/no) and migraine (yes/no), which are associated with both migraine and neck/shoulder pain, were included as possible confounders in the main analysis.

Prevalence with binomial confidence intervals (CIs) for self-reported pain by frequency of migraine categories was calculated.

The association between neck/shoulder pain and frequency of migraine was assessed in multinomial regression models with frequency as the dependent variable (reference: no headache) and neck/shoulder pain as the independent variable. Odds ratios (ORs) with 95\% CIs and stepwise adjustment for confounders were calculated (statistical software R, version 3.1.0).

\section{Results}

In total 601 of the 1674 students aged 12-19 years (mean age $=14.54, \mathrm{SD}=1.18$ ) with migraine or without any headache in the last six months were included in this analysis (Figure 1). Headache frequency was on average 10.57 days $(\mathrm{SD}=10.17)$ in the last three months with a mean intensity of $5.69(\mathrm{SD}=2.02)$ on a 10-point Likert scale. Of 360 students with migraine 99 had migraine less than once a week, 195 had weekly migraine and 66 fulfilled the criteria for chronic migraine (Table 1).

Associations $(p<0.1)$ with both neck/shoulder pain and migraine were found for gender (female), stress, coffee and alcohol consumption, and smoking (Table 1).

The prevalence of self-reported regional pain increased with increased frequency of migraine as follows: $33.6 \%$ for students without headache, $45.5 \%$ for adolescents with migraine less than once a week, $58.47 \%$ for students with weekly migraine, and $84.9 \%$ in adolescents with chronic migraine (test for trends: $p<0.0001$ ) (Figure 2).

While there was no association between self-reported neck/shoulder pain and migraine less than once a week after adjustment for confounding, a clear association was observed for weekly migraine $(\mathrm{OR}=2.37,95 \%$ $\mathrm{CI}=(1.42-3.24))$ that further increased for chronic migraine $(\mathrm{OR}=7.27,95 \% \mathrm{CI}=(3.42-15.44))$ (Table 2$)$.

\section{Discussion}

The key finding of our study is the 2.4-fold increased risk in adolescents with episodic migraine (at least weekly) and the seven-fold increased risk in adolescents 
with chronic migraine of self-reported shoulder/neck pain, when taking confounding by other risk factors into account. In a previous study, an association of self-reported neck pain with migraine was found while

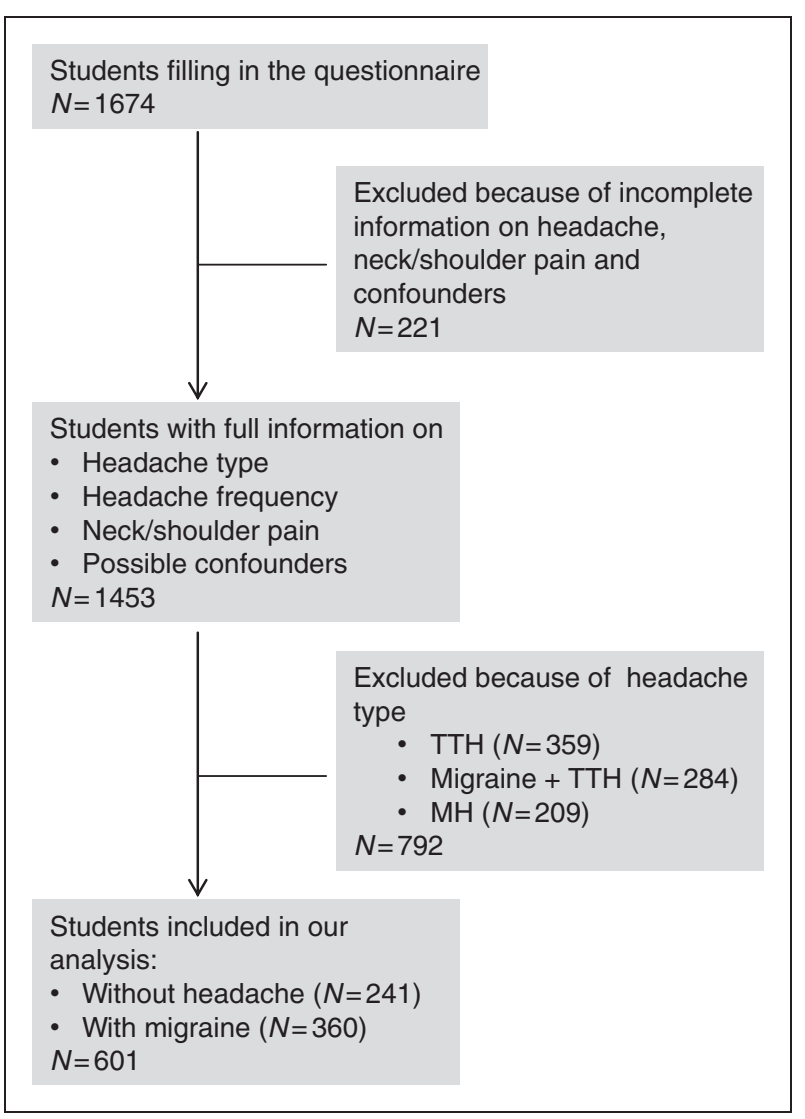

Figure I. Flowchart of the study sample.

TTH: tension-type headache; $\mathrm{MH}$ : migraine headache. the observed association of neck pain with isolated tension-type headache (TTH) could be explained by confounding (2). The present study found that selfreported neck pain is more strongly associated with chronic than with episodic migraine. Other studies also pointed to the association between neck pain and migraine (e.g. Grimmer et al. (6) and Blaschek et al. (7)), but no differentiation between episodic and chronic migraine was made. Even if there are studies in adults assessing the association of neck pain and migraine frequency (8-10), this association has not been evaluated in adolescents yet.

Since the association between migraine, in particular chronic migraine, and self-reported neck/shoulder pain was only partially attenuated by adjustment for confounders like stress, a biologically independent association between regional pain and chronic migraine can be assumed.

Several hypothetical explanations for the association of migraine and neck/shoulder pain are discussed in the literature. Migraine is seen as the result of trigeminovascular activation (11) leading to increased neuronal activity in the caudal trigeminal nucleus. There is also a strong convergence on these neurons by nociceptive afferents from the upper cervical structures (the TCC (3)). Another brain area with electrophysiological convergence from the somatic and trigeminal sensory neurons is the posterior thalamus (12).

Patients with chronic migraine report neck/shoulder pain more often than patients with episodic migraine or healthy controls. One hypothesis is that relapsing pain attacks induce increased muscle tone via the limbic system (13) and a higher number of trigger points (8) and subsequently a sensitization at afferent pathways. These nociceptive afferents may again trigger recurrent

Table I. Prevalence of possible confounders for the association between self-reported neck and shoulder pain and migraine $(N=60 I)$.

\begin{tabular}{|c|c|c|c|c|c|c|}
\hline & \multicolumn{2}{|l|}{$\%(N)$ or $M(S D)$} & \multirow[b]{2}{*}{$p$ value } & \multicolumn{2}{|c|}{$\%(N)$ or $M(S D)$} & \multirow[b]{2}{*}{$p$ value } \\
\hline & $\begin{array}{l}\text { Students with } \\
\text { neck/shoulder pain } \\
N=296\end{array}$ & $\begin{array}{l}\text { Students without } \\
\text { neck/shoulder pain } \\
N=305\end{array}$ & & $\begin{array}{l}\text { Students with } \\
\text { migraine } \\
N=360\end{array}$ & $\begin{array}{l}\text { Students without } \\
\text { headache } \\
N=24 \text { I }\end{array}$ & \\
\hline Gender (female) & $67.72(172)$ & $50.98(104)$ & $<0.001$ & $64.17(231)$ & $41.08(99)$ & $<0.001$ \\
\hline Age & I4.56 (I.23) & I4.44 (I.II) & 0.188 & $14.55(1.16)$ & I4.45 (I.I7) & 0.31 \\
\hline Chronic stress & $41.20(103)$ & $20.8 I(4 I)$ & $<0.00 \mathrm{I}$ & $35.90(126)$ & $14.04(33)$ & $<0.001$ \\
\hline Consumption of alcohol & $53.60(134)$ & $49.75(98)$ & 0.084 & $52.71(185)$ & $42.98(101)$ & 0.03 \\
\hline Coffee consumption & $50.40(126)$ & $48.22(95)$ & 0.073 & $50.7 \mid(\mid 78)$ & $36.17(85)$ & $<0.001$ \\
\hline $\begin{array}{l}\text { Consumption of soft } \\
\text { drinks containing caffeine }\end{array}$ & $72.40(181)$ & $71.07(140)$ & 0.498 & $70.94(249)$ & $67.23(158)$ & 0.39 \\
\hline Smoking & $18.00(45)$ & |3.7| (27) & 0.059 & I7.37 (6I) & $10.64(25)$ & 0.03 \\
\hline Physical inactivity & $23.20(58)$ & $22.34(44)$ & 0.287 & $23.08(8 I)$ & $22.55(53)$ & 0.96 \\
\hline
\end{tabular}




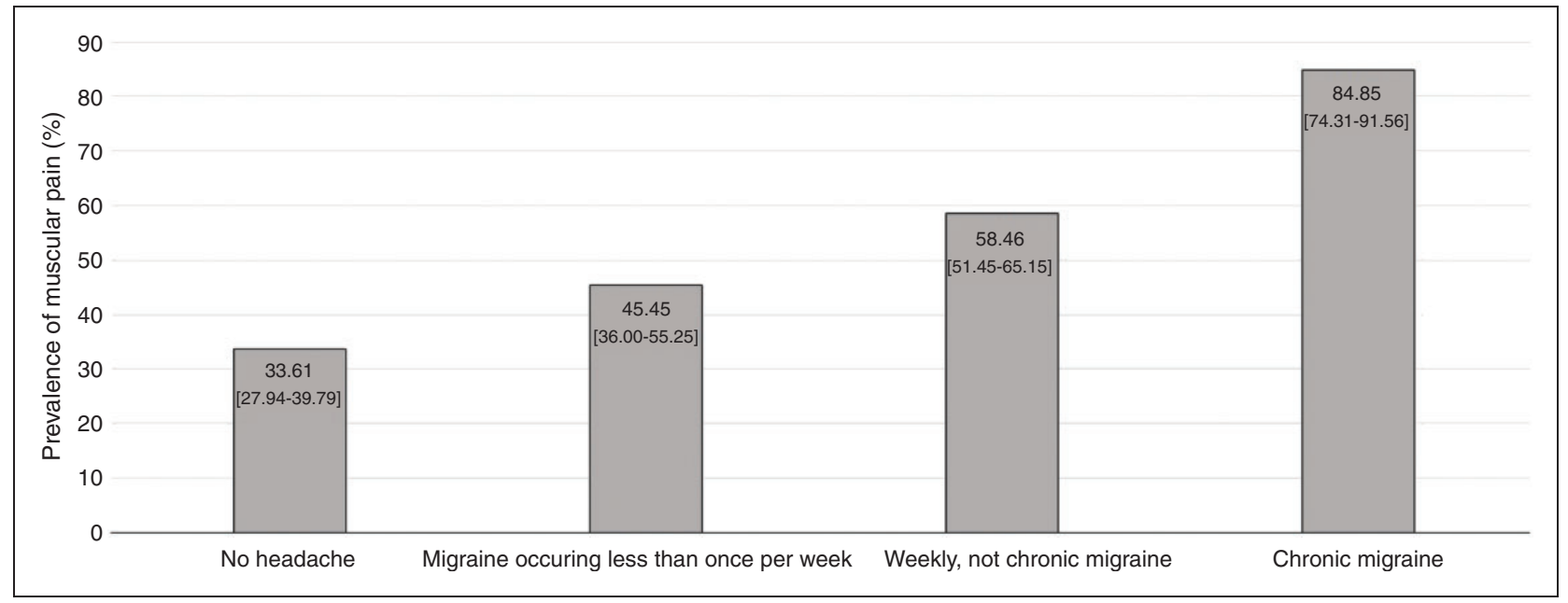

Figure 2. Prevalence of self-reported pain in the neck and shoulder region stratified for frequency of migraine.

Table 2. Association between self-reported neck and shoulder pain and frequency of migraine (reference no headache)—multinomial regression model adjusted for sex, grade and other risk factors for migraine.

\begin{tabular}{|c|c|c|c|}
\hline & \multicolumn{3}{|l|}{ Migraine } \\
\hline & $\begin{array}{l}\text { Less than once per month } \\
N=99\end{array}$ & $\begin{array}{l}\text { Weekly, not chronic } \\
N=195\end{array}$ & $\begin{array}{l}\text { Chronic } \\
N=66\end{array}$ \\
\hline Self-reported neck and shoulder pain (yes vs. no) & & OR $(95 \% \mathrm{Cl})$ & \\
\hline Univariate model & $\begin{array}{l}1.65 \\
(1.02-2.65)\end{array}$ & $\begin{array}{l}2.78 \\
(1.88-4.11)\end{array}$ & $\begin{array}{l}11.06 \\
(5.36-22.82)\end{array}$ \\
\hline+ Adjusted for sex and grade & $\begin{array}{l}1.63 \\
(1.01-2.64)\end{array}$ & $\begin{array}{l}2.50 \\
(1.68-3.73)\end{array}$ & $\begin{array}{l}9.15 \\
(4.37-19.17)\end{array}$ \\
\hline+ Adjusted for stress & $\begin{array}{l}1.54 \\
(0.94-2.53)\end{array}$ & $\begin{array}{l}2.37 \\
(1.56-3.58)\end{array}$ & $\begin{array}{l}7.50 \\
(3.53-15.96)\end{array}$ \\
\hline + Adjusted for smoking, alcohol and coffee consumption & $\begin{array}{l}1.40 \\
(0.85-2.30)\end{array}$ & $\begin{array}{l}2.14 \\
(1.42-3.24)\end{array}$ & $\begin{array}{l}7.27 \\
(3.42-15.44)\end{array}$ \\
\hline
\end{tabular}

migraine attacks. A sensitization at the level of the second- and third-order neurons could also account for the higher frequency of migraine in patients with neck/shoulder pain (3).

Thus, there may be several sites in the nociceptive system where convergent information from the cephalic and extracephalic system can be found and where increased nociceptive input from extracephalic areas (e.g. neck/shoulder) may lower the activation threshold because of nociceptive afferents from the trigemino-vascular system. Therefore it might be beneficial to reduce the nociceptive input from these extracephalic structures in order to reduce the frequency of migraine attacks.

\section{Strengths and limitations}

A strength of this study is its sample size, which provides sufficient cases to disentangle the association between self-reported neck/shoulder pain and infrequent/frequent migraine because CIs for chronic migraine did not overlap with CIs for weekly migraine or migraine less than once a week. The subgroup of students with chronic migraine, however, is quite small, which causes wide CIs and must be considered in the interpretation of the results.

A limitation of the study might be the assessment of neck/shoulder pain. Prevalence of pain was self-rated and assessed by a questionnaire, not based on a medical examination. Therefore random misclassification appears possible, but would instead account for bias with unity. Similarly, headache was classified by a questionnaire only. Several studies, however, have confirmed that headache questionnaires have an adequate sensitivity, specificity and predictive value regarding clinical diagnosis (14-16). 
The external validity of our results is limited as our study population consisted of students from an urban area in Germany.

Because of the cross-sectional design of this study, it is not yet possible to confirm whether neck/shoulder pain predicts migraine.

\section{Conclusion}

In adolescents the association between self-reported neck/shoulder pain and migraine is most pronounced in migraine with a high attack frequency. A trend analysis shows that the prevalence of self-reported regional pain increased with the frequency of migraine: $33.6 \%$ of students without headache, 45.5 $\%$ of adolescents with migraine less than once a week, $58.5 \%$ of students with weekly migraine and $84.9 \%$ of adolescents with chronic migraine reported neck/shoulder pain.

\section{Clinical implications}

- Self-reported pain in the neck and shoulder area is associated with migraine in adolescents.

- The association of this self-reported pain is stronger in individuals with a high frequency of migraine (chronic migraine) compared to patients with a lower frequency of attacks (episodic migraine).

\section{Acknowledgments}

We thank the German Center for Vertigo and Balance Disorders (DSGZ) and all participants and schools for their support. We thank Mrs K. Ogston for the English language editing.

\section{Declaration of conflicting interests}

The authors declared no potential conflicts of interest with respect to the research, authorship, and/or publication of this article.

\section{Funding}

This work was partially supported by the German Headache and Migraine Society (DMKG).

\section{References}

1. Fendrich K, Vennemann M, Pfaffenrath V, et al. Headache prevalence among adolescents-The German DMKG headache study. Cephalalgia 2007; 27: 347-354.

2. Blaschek A, Decke S, Albers L, et al. Self-reported neck pain is associated with migraine but not with tension-type headache in adolescents. Cephalalgia 2014; 34: 895-903.

3. Bartsch T and Goadsby PJ. Central mechanisms of peripheral nerve stimulation in headache disorders. Prog Neurol Surg 2011; 24: 16-26.

4. Headache Classification Committee of the International Headache Society (IHS). The International Classification of Headache Disorders, 3rd edition (beta version). Cephalalgia 2013; 33: 629-808.

5. Yoon MS, Obermann M, Fritsche G, et al. Populationbased validation of a German-language selfadministered headache questionnaire. Cephalalgia 2008; 28: 605-608.
6. Grimmer K, Nyland L and Milanese S. Repeated measures of recent headache, neck and upper back pain in Australian adolescents. Cephalalgia 2006; 26: 843-851.

7. Blaschek A, Milde-Busch A, Straube A, et al. Selfreported muscle pain in adolescents with migraine and tension-type headache. Cephalalgia 2012; 32: 241-249.

8. Calandre EP, Hidalgo J, García-Leiva JM, et al. Trigger point evaluation in migraine patients: An indication of peripheral sensitization linked to migraine predisposition? Eur J Neurol 2006; 13: 244-249.

9. Florencio LL, Chaves TC, Carvalho GF, et al. Neck pain disability is related to the frequency of migraine attacks: A cross-sectional study. Headache 2014; 54: 1203-1210.

10. Carvalho GF, Chaves TC, Gonçalves MC, et al. Comparison between neck pain disability and cervical range of motion in patients with episodic and chronic migraine: A cross-sectional study. J Manipulative Physiol Ther 2014; 37: 641-646.

11. Pietrobon D and Moskowitz MA. Pathophysiology of migraine. Annu Rev Physiol 2013; 75: 365-391.

12. Burstein R, Jakubowski M, Garcia-Nicas E, et al. Thalamic sensitization transforms localized pain into widespread allodynia. Ann Neurol 2010; 68: 81-91.

13. Sauro KM and Becker WJ. The stress and migraine interaction. Headache 2009; 49: 1378-1386.

14. Anttila P, Metsähonkala L, Mikkelsson M, et al. Muscle tenderness in pericranial and neck-shoulder region in children with headache. A controlled study. Cephalalgia 2002; 22: 340-344.

15. Valentinis L, Valent F, Mucchiut M, et al. Migraine in adolescents: Validation of a screening questionnaire. Headache 2009; 49: 202-211.

16. Zarifoğlu M, Karli $\mathrm{N}$ and Taşkapilioğlu O. Can ID Migraine be used as a screening test for adolescent migraine? Cephalalgia 2008; 28: 65-71. 